\title{
Comparing Adherence and Persistence Across 6 Chronic Medication Classes
}

\author{
Jason Yeaw, MPH; Joshua S. Benner, PharmD, ScD; John G. Walt, MBA; \\ Sergey Sian, PhD; and Daniel B. Smith, MA
}

\begin{abstract}
BACKGROUND: The National Quality Forum recently endorsed the proportion of days covered (PDC) - a measure of medication adherence-as an indicator of quality in drug therapy management.

OBJECTIVE: To inform initial efforts to improve the quality of drug therapy management, we compared PDC and persistence among new users of 6 commonly used chronic medication categories.

METHODS: A retrospective analysis of pharmacy claims in a database of more than 64 million members enrolled in 100 health plans assessed persistence and adherence to drug therapy in 6 chronic conditions. Patients were included in the analysis if they initiated a prescription drug of interest in any of 6 drug classes-prostaglandin analogs, statins, bisphosphonates, oral antidiabetics, angiotensin II receptor blockers (ARBs), and overactive bladder (OAB) medications-between January 1 and December 31, 2005. The first claim for a drug of interest during this period was considered a patient's index date. Patients were required to have a minimum of 12 months of continuous enrollment both preceding and following their index date. New users of a treatment were identified by excluding patients who filled a prescription for any drug in the same class during the previous 12 months and were followed for a minimum of 12 months. Nonpersistence was defined as discontinuation of the therapy class following an allowed gap between refills-30-, 60-, and 90-day refill gaps were used.

Adherence was defined as a continuous measure of the proportion of days covered (PDC) during the 12-month post-index period. Logistic regression analyses predicted (a) nonpersistence during the 12-month post-index period and (b) adherence (PDC) of at least $80 \%$, with drug class as the predictor variable of interest, controlling for demographic variables, insurance and plan type, history of hospitalization, Charlson comorbidity score, copayment for index medication, and number of medications at index.
\end{abstract}

RESULTS: A total of 167,907 patients were identified across 6 cohorts. Using the 60-day gap, 6-month persistence rates were prostaglandin analogs $47 \%$, statins $56 \%$, bisphosphonates $56 \%$, oral antidiabetics $66 \%$, ARBs $63 \%$, and $O A B$ medications $28 \%$. After the first 90 days of therapy, relative persistence was stable across cohorts, and rates declined consistently from 6 months post-index to study end. Logistic regression models showed that oral antidiabetic users had a $59 \%, 36 \%, 37 \%$, and $79 \%$ decreased risk of nonpersistence in a 12-month follow-up period compared with patients taking prostaglandin analogs, statins, bisphosphonates, or $O A B$ medications, respectively. Risk of nonpersistence decreased with increasing age. Mean (SD) 12-month adherence rates were: prostaglandin analogs $37 \%(26 \%)$, statins $61 \%(33 \%)$, bisphosphonates $60 \%(34 \%)$, oral antidiabetics $72 \%(32 \%)$, ARBs $66 \%(32 \%)$, and OAB medications $35 \%$ $(32 \%)$. Logistic regression indicated that oral antidiabetic use was a significant predictor of adherence (PDC) of at least $80 \%$ compared with other therapy classes. Adjusted odds ratios for oral antidiabetics were 17.60 (95\% confidence interval $[\mathrm{Cl}]=15.38-20.14)$ versus prostaglandin analogs, $2.06(95 \% \mathrm{Cl}=1.99-2.12)$ versus statins, $1.92(95 \% \mathrm{Cl}=1.83-2.02)$ versus bisphosphonates, $1.29(95 \% \mathrm{Cl}=1.24-1.34)$ versus ARBs, and $5.77(95 \%$ $\mathrm{Cl}=5.38-6.19)$ versus $\mathrm{OAB}$ medications.
CONCLUSION: This analysis of adherence (PDC) and persistence across a sample of 6 chronic therapies found variable but uniformly suboptimal medication use. Adherence to prostaglandin eye drops and $\mathrm{OAB}$ medications was lower than to cardiovascular, oral antidiabetic, and oral osteoporosis therapies. These findings provide useful baseline information for the development of initiatives to improve the quality of drug therapy management.

J Manag Care Pharm. 2009;15(9):728-40

Copyright $\odot$ 2009, Academy of Managed Care Pharmacy. All rights reserved.

\section{What is already known about this subject}

- The National Quality Forum recently endorsed medication adherence—specifically, the proportion of days covered (PDC) —as an indicator of quality in drug therapy management.

- Existing analyses of persistence and adherence are of limited use in quality improvement efforts because they use a variety of metrics and rarely compare persistence and adherence across multiple chronic therapies.

\section{What this study adds}

- This study is, to the best of our knowledge, the first attempt to measure the PDC in multiple chronic therapeutic areas.

- In this analysis of patients new to their therapeutic class, mean 12-month adherence rates (based on PDC calculations) were as follows: prostaglandin analogs $37 \%$, statins $61 \%$, bisphosphonates $60 \%$, oral antidiabetics $72 \%$, angiotensin II receptor blockers $66 \%$, and overactive bladder medications $35 \%$.

- This study provides nationally representative baseline adherence information for commercially insured individuals, identifies substantial differences across therapy areas, and suggests important opportunities to improve the quality of drug therapy management.

$\mathrm{N}$ onadherence to prescription medications has received increased attention as a public health problem. In 2003, the World Health Organization identified medication nonadherence as a leading cause of preventable morbidity, mortality, and health care costs. ${ }^{1}$ A recent report by the New England Healthcare Institute estimated the burden of nonadherence, along with suboptimal diagnosis, prescribing, and medication administration, to be $\$ 290$ billion per year. ${ }^{2}$ In 2007 , the National Council on Patient Information and Education issued a "National Action Plan" that called for efforts on the part of all stakeholders to improve medication adherence. ${ }^{3}$ One potentially important 
step forward in addressing the problem of nonadherence came in 2009 when the National Quality Forum endorsed 18 measures to assess prescribing and use of appropriate medications. ${ }^{4}$ Six of the 18 quality measures assess medication adherence via the proportion of days covered (PDC) in the therapeutic categories of statins, calcium channel blockers, angiotensin II receptor blockers (ARBs) and angiotensin-converting enzyme (ACE) inhibitors, oral antidiabetic drugs, and antipsychotics. The development of adherence-related quality measures is intended to enable quality improvement programs that align patient, provider, and payer incentives toward optimal use of specific prescribed therapies.

Efforts to improve therapy management in general and adherence in particular should be informed by current, representative, and consistent benchmark data on adherence levels in therapeutic classes of interest. Such data would describe the magnitude of nonadherence, identify differences across treatment categories, and facilitate priority setting for new interventions. Unfortunately, such data are scarce because most adherence and persistence analyses focus on a single drug or drug class. ${ }^{5-7}$ Even recent research comparing across-treatment adherence rates for medications to treat epilepsy, diabetes, dyslipidemia, and hypertension have been limited to within-class comparisons. ${ }^{8-11}$ In one exception, a 2008 study by Briesacher et al. analyzed medication possession ratios (MPRs) in 7 different chronic disease cohorts; prior to this research, the last major study to apply a consistent methodology to compare adherence rates across therapeutic areas was published more than 20 years ago. ${ }^{8,12}$ To our knowledge, no comparative adherence studies have been performed using the PDC.

The objective of this analysis was to assess variations in adherence and persistence-based on widely used measures, including PDC - in a large, heterogenous patient population for $6 \mathrm{com}-$ monly used chronic medication classes: prostaglandin analogs (indicated for glaucoma), statins (hyperlipidemia), bisphosphonates (osteoporosis), oral antidiabetic drugs (type 2 diabetes), ARBs (hypertension), and antimuscarinics (overactive bladder $[O A B])$. These therapeutic categories were selected because they are widely used chronic medication classes, each is used to treat a burdensome and costly chronic condition, and adherence has been shown to be suboptimal. ${ }^{13-18}$ Therefore, these drug classes rank high among future, potential candidates for adherence interventions.

\section{Methods}

\section{Data Source}

Data were gathered from the PharMetrics Patient-Centric Database, ${ }^{19}$ a nationally representative database that includes fully adjudicated medical and pharmaceutical claims from more than 64 million individual members enrolled in 100 U.S. health plans (approximately 16 million covered enrollees per year). The database includes both inpatient and outpatient diagnoses (in International Classification of Diseases, Ninth Revision,
Clinical Modification [ICD-9-CM] format); procedures (in Current Procedural Terminology, 4th edition [CPT-4] and Healthcare Common Procedure Coding System [HCPCS] formats); and retail and mail order pharmacy claims. Available data on pharmacy claims include the National Drug Code (NDC) as well as the quantity of the medication dispensed. Both paid and charged amounts are available for all services rendered, as well as dates of service for all medical and pharmacy claims. Additional data elements available in the database include demographic variables (age, gender, and geographic region), product type (e.g., health maintenance organization [HMO], preferred provider organization [PPO]), payer type (e.g., commercial, self-insured), provider specialty, and beginning and ending dates of health plan enrollment. Records in the PharMetrics database are generally representative of the national, commercially insured population in terms of age, gender, and type of health plan. The data are also longitudinal, with an average duration of member enrollment of 2 years.

\section{Patients}

Patients were included in the analysis if they initiated a retail or mail-order prescription drug of interest (Table 1) between January 1 and December 31, 2005. The first claim for a drug of interest during this period was considered a patient's index date, and patients were not required to have subsequent prescriptions for inclusion. New users of a treatment were identified by excluding patients who filled a prescription for any drug in the same class (or therapeutic equivalent) during the previous 12 months. Patients in the oral antidiabetic group with pre-index pharmacy claims for insulin were excluded, as were ARB patients with preindex pharmacy claims for ACE inhibitors, as these medications are viewed as therapeutically equivalent to their respective index medications. Patients were also required to have a minimum of 12 months of continuous enrollment during both the pre- and post-index periods (total of 24 months of continuous enrollment). Additionally, patients could have had up to 12 additional (total of 24 post-index) months of follow-up for the unadjusted assessment of persistence only. For patients initiated on more than 1 medication class of interest during 2005, only the first medication within the time period was selected and assessed as the index medication.

An ICD-9-CM diagnosis code for the chronic disease associated with its respective medication cohort was required in the pre-index period to ensure appropriate indication (glaucoma, ICD-9-CM codes 365.xx; disorders of lipoid metabolism, ICD9-CM codes 272.xx; osteoporosis, ICD-9-CM codes 733.0x; diabetes mellitus, ICD-9-CM codes 250.xx; hypertensive disease, ICD-9-CM codes 401.xx-404.xx; OAB, ICD-9-CM codes 596.51, 596.52, 596.55, 596.59, 788.3x, 788.41, 788.43, and 788.63). Other exclusions included patients with any claim containing an invalid days supply value (defined as a value of zero, a negative integer, or missing during the post-index period) and patients for 
Comparing Adherence and Persistence Across 6 Chronic Medication Classes

\section{TABLE 1 Study Medications and Prescription Sample Sizes for Each Cohort}

\begin{tabular}{|c|c|c|c|}
\hline Drug Cohorts & $\begin{array}{c}\text { Number of } \\
\text { Pharmacy Claims }\end{array}$ & Drug Cohorts & $\begin{array}{c}\text { Number of } \\
\text { Pharmacy Claims }\end{array}$ \\
\hline \multicolumn{2}{|l|}{ Prostaglandin analogs } & \multicolumn{2}{|l|}{ Oral antidiabetics (continued) } \\
\hline Latanoprost & 7,603 & Glimepiride & 8,658 \\
\hline Travoprost & 1,662 & Glyburide & 7,035 \\
\hline Bimatoprost & 747 & Glyburide-metformin & 6,111 \\
\hline Total & 10,012 & Rosiglitazone maleate-metformin $\mathrm{Hcl}$ & 3,917 \\
\hline \multicolumn{2}{|l|}{ Statins } & Nateglinide & 837 \\
\hline Atorvastatin calcium & 166,764 & Repaglinide & 759 \\
\hline Simvastatin & 44,015 & Total & 118,091 \\
\hline Ezetimibe-simvastatin & 45,874 & \multicolumn{2}{|l|}{ ARBs } \\
\hline Rosuvastatin calcium & 32,104 & Losartan potassium \& hydrochlorothiazide & 58,584 \\
\hline Lovastatin & 25,242 & Valsartan & 20,600 \\
\hline Pravastatin sodium & 15,047 & Olmesartan medoxomil & 14,081 \\
\hline Fluvastatin sodium & 4,738 & Losartan potassium & 9,411 \\
\hline Aspirin buffered-pravastatin sodium & 3,837 & Irbesartan & 9,753 \\
\hline ( & 337,621 & Telmisartan & 3,711 \\
\hline \multicolumn{2}{|l|}{ Bisphosphonates } & Candesartan cilexetil & 3,190 \\
\hline Alendronate sodium & 21,420 & Eprosartan mesylate & 654 \\
\hline Risedronate sodium & 13,549 & Total & 119,984 \\
\hline Ibandronate sodium & 2,532 & \multicolumn{2}{|l|}{ OAB medications } \\
\hline Zoledronic acid & 11 & Tolterodine tartrate & 9,487 \\
\hline Etidronate disodium & 11 & Oxybutynin chloride & 7,340 \\
\hline Pamidronate disodium & 2 & Solifenacin succinate & 1,640 \\
\hline Total & 37,525 & Darifenacin hydrobromide & 968 \\
\hline \multicolumn{2}{|l|}{ Oral antidiabetics } & Trospium chloride & 771 \\
\hline Metformin Hcl & 54,546 & Bethanechol chloride & 305 \\
\hline Glipizide & 13,134 & Flavoxate Hcl & 165 \\
\hline Pioglitazone $\mathrm{Hcl}$ & 11,764 & Hyoscyamine & 13 \\
\hline Rosiglitazone maleate & 11,330 & Total & 20,689 \\
\hline
\end{tabular}

whom complete utilization records were not available. To ensure the availability of complete claims histories, patients aged 65 years or older were restricted to those enrolled in Medicare "risk" plans. Details of inclusion and exclusion criteria are included in the flow chart shown in Figure 1.

\section{Measurements}

Persistence. Patient persistence within the index class of medication was calculated for the post-index period until the patient discontinued therapy, was lost to follow-up due to disenrollment from the health plan (minimum of 12 months), or the maximum 24-month follow-up period ended, whichever event occurred first. A patient was considered persistent until an excessive gap in days supplied occurred; refill gaps of 30,60, and 90 days were used to calculate persistence for all cohorts. The end date of persistence was considered the date on which the last prescription's days supply should have ended. Medication persistence was evaluated at a class level; patients who switched products within their index medication class but did not exceed the permissible gap were considered persistent. Patients in the oral antidiabetic cohort who switched to insulin during the follow-up period were considered persistent; likewise, patients in the ARB cohort who switched to ACE inhibitors during the follow-up period were also considered to be persistent, as these medication classes were considered to be therapeutically equivalent and interchangeable for the purposes of this analysis.

In order to establish consistency with respect to adherence rules, only 2.5 milliliter $(\mathrm{ml})$ bottles of prostaglandin analogs were included in the analysis; patients with prescriptions for bottle sizes other than $2.5 \mathrm{ml}$ were excluded from the analysis. This decision rule allowed us to assign a reasonable grace period for patient refills and also served to minimize the potential for variability in number of doses per prescription. All prostaglandin analog eye drop prescriptions included in the study were assumed to have a 60-day supply.

Adherence. Adherence was measured using the PDC for each of the 6 drug class cohorts. This was calculated by taking patients' total days supplied of index class medications for the 360-day 


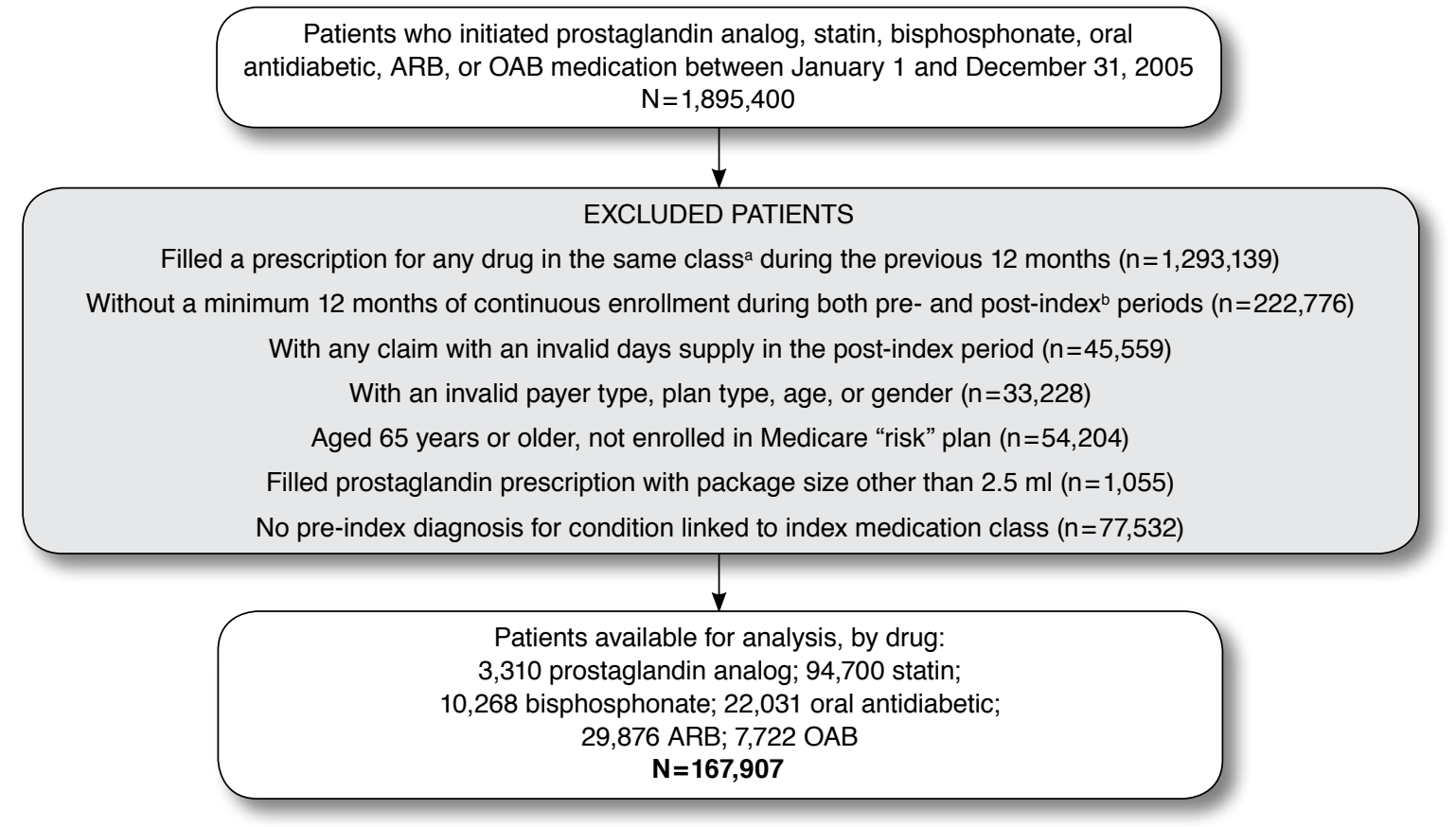

aFor the oral antidiabetic and ARB classes, patients with pre-index use of insulin and ACE inhibitors, respectively, were also removed.

Index date was the date on which the first prescription for any medication of interest (see Table 1) was filled. For patients initiated on more than 1 medication class of interest during 2005, only the first medication within the time period was selected and assessed as the index medication.

$A C E=$ angiotensin-converting enzyme; $A R B=$ angiotensin II receptor blocker; $m l=$ milliliter; $O A B=$ overactive bladder .

period following the index date and dividing by 360 . Using this method, adherence was based on the entire year and not only on patients' persistent periods. For all unadjusted measures of PDC, the medication cohort values were calculated and reported on a continuous scale, with values from $0 \%$ to $100 \%$ and no minimum threshold (e.g., 80\% PDC). Days affected by overlapping prescriptions, as in the case of early refills, were assessed based on the assumption that the prior supply was taken fully before the new supply was initiated. The start date of days supplied for a refill was delayed until the supply for the prior prescription had been exhausted. Additionally, prescriptions extending beyond the end of the 12-month follow-up were truncated at the index plus 360day mark (maximum PDC $=100 \%$ ).

\section{Statistical Analysis}

Patient persistence was reported using Kaplan-Meier plots of time to discontinuation for the minimum 12-month and maximum 24-month follow-up period. Continuous measure (minimum $0 \%$, maximum $100 \%$ ) PDC calculations were used to generate medication cohort mean, median, and standard deviation for the 1-year post-index period.

In order to quantify differences in persistence and adherence across treatments, we conducted multivariate regression analyses using drug class as an indicator variable with the oral antidiabetic cohort as the reference and each of the other classes as comparator groups. For ease of interpretation, the multiplicative inverse of each group-specific parameter estimate was calculated and presented in the tables. For the persistence comparison, we employed a logistic regression model, with results reported as odds ratios. The outcome of interest was nonpersistence, that is, discontinuation of the index class within 360 days post-index. Logistic regression analysis of nonpersistence within 360 days was used instead of Cox proportional hazards analysis because (a) visual inspection of Kaplan-Meier curves suggested nonproportional hazards in the first 60-120 days of therapy, making Cox regression analysis inappropriate; and (b) the 360-day time period is consistent with previous work and with recently defined National Quality Forum standards., ${ }^{42}$ For the adherence comparison, we used a logistic regression model in which the outcome of interest was a PDC of $80 \%$ or more in the 360 -day post-index period.

For both logistic regression models, the following were included as independent variables in addition to drug class: gender, age, geographic region, plan type (indemnity, $\mathrm{HMO}, \mathrm{PPO}$, 
Comparing Adherence and Persistence Across 6 Chronic Medication Classes

TABLE 2 Baseline Characteristics of New Users for Each Drug Category

\begin{tabular}{|c|c|c|c|c|c|c|c|c|c|c|c|c|}
\hline Characteristic & \multicolumn{2}{|c|}{$\begin{array}{c}\text { Prostaglandin } \\
\text { Analogs } \\
(\mathbf{n}=3,310) \\
\end{array}$} & \multicolumn{2}{|c|}{$\begin{array}{c}\text { Statins } \\
(\mathrm{n}=94,700)\end{array}$} & \multicolumn{2}{|c|}{$\begin{array}{c}\text { Bisphosphonates } \\
(\mathrm{n}=10,268)\end{array}$} & \multicolumn{2}{|c|}{$\begin{array}{c}\text { Oral } \\
\text { Antidiabetics } \\
(\mathrm{n}=22,031)\end{array}$} & \multicolumn{2}{|c|}{$\begin{array}{c}\text { ARBs } \\
(\mathrm{n}=29,876)\end{array}$} & \multicolumn{2}{|c|}{$\begin{array}{c}\text { OAB } \\
\text { Medications } \\
(\mathbf{n}=7,722)\end{array}$} \\
\hline \multicolumn{13}{|l|}{ Age } \\
\hline Mean & 55.4 & & 52.5 & & 56.9 & & 51.6 & & 51.1 & & 43.7 & \\
\hline SD & 11.6 & & 9.1 & & 7.9 & & 10.5 & & 10.0 & & 18.3 & \\
\hline \multicolumn{13}{|l|}{ Gender (n, \%): } \\
\hline Male & 1,512 & $45.7 \%$ & 51,814 & $54.7 \%$ & 565 & $5.5 \%$ & 11,791 & $53.5 \%$ & 14,456 & $48.4 \%$ & 1,686 & $21.8 \%$ \\
\hline \multicolumn{13}{|l|}{ Plan type (n, \%): } \\
\hline $\mathrm{HMO}$ & 1,098 & $33.2 \%$ & 27,040 & $28.6 \%$ & 3,029 & $29.5 \%$ & 6,410 & $29.1 \%$ & 6,399 & $21.4 \%$ & 2,404 & $31.1 \%$ \\
\hline Indemnity & 159 & $4.8 \%$ & 4,574 & $4.8 \%$ & 685 & $6.7 \%$ & 876 & $4.0 \%$ & 1,774 & $5.9 \%$ & 330 & $4.3 \%$ \\
\hline POS & 418 & $12.6 \%$ & 10,226 & $10.8 \%$ & 1,298 & $12.6 \%$ & 2,295 & $10.4 \%$ & 3,437 & $11.5 \%$ & 1,030 & $13.4 \%$ \\
\hline $\mathrm{PPO}$ & 1,505 & $45.5 \%$ & 48,748 & $51.5 \%$ & 4,779 & $46.5 \%$ & 11,430 & $51.9 \%$ & 16,829 & $56.3 \%$ & 3,733 & $48.3 \%$ \\
\hline Other/unknown & 130 & $3.9 \%$ & 4,112 & $4.3 \%$ & 477 & $4.6 \%$ & 1,020 & $4.6 \%$ & 1,437 & $4.8 \%$ & 225 & $2.9 \%$ \\
\hline \multicolumn{13}{|l|}{ Payer type (n, \%): } \\
\hline Commercial & 2,867 & $86.6 \%$ & 87,985 & $92.9 \%$ & 9,216 & $89.8 \%$ & 20,152 & $91.5 \%$ & 28,090 & $94.0 \%$ & 7,023 & $90.9 \%$ \\
\hline Medicaid & 20 & $0.6 \%$ & 420 & $0.4 \%$ & 29 & $0.3 \%$ & 236 & $1.1 \%$ & 31 & $0.1 \%$ & 126 & $1.6 \%$ \\
\hline Medicare risk & 316 & $9.5 \%$ & 2,446 & $2.6 \%$ & 661 & $6.4 \%$ & 795 & $3.6 \%$ & 812 & $2.7 \%$ & 297 & $3.8 \%$ \\
\hline Self-insured & 86 & $2.6 \%$ & 3,463 & $3.7 \%$ & 298 & $2.9 \%$ & 769 & $3.5 \%$ & 804 & $2.7 \%$ & 250 & $3.2 \%$ \\
\hline Other/unknown & 21 & $0.6 \%$ & 386 & $0.4 \%$ & 64 & $0.6 \%$ & 79 & $0.4 \%$ & 139 & $0.5 \%$ & 26 & $0.3 \%$ \\
\hline \multicolumn{13}{|c|}{ Charlson comorbidity score ${ }^{a}$} \\
\hline Mean & 0.5 & & 0.6 & & 0.6 & & 1.4 & & 0.6 & & 0.5 & \\
\hline SD & 1.1 & & 1.1 & & 1.2 & & 1.2 & & 1.1 & & 1.2 & \\
\hline \multicolumn{13}{|c|}{ Hospitalization in baseline year ${ }^{b}(n, \%)$ : } \\
\hline$\geq 1$ hospitalization & 208 & $6.3 \%$ & 9,405 & $9.9 \%$ & 823 & $8.0 \%$ & 2,437 & $11.1 \%$ & 2,559 & $8.6 \%$ & 958 & $12.4 \%$ \\
\hline \multicolumn{13}{|c|}{ Number of medications on hand at index date ${ }^{c}$} \\
\hline Mean & 2.6 & & 3.0 & & 2.8 & & 3.4 & & 2.7 & & 3.1 & \\
\hline $\mathrm{SD}$ & 2.0 & & 2.0 & & 2.1 & & 2.2 & & 1.9 & & 2.2 & \\
\hline \multicolumn{13}{|c|}{ Copayment for index medication $^{\mathrm{d}}$} \\
\hline Mean & $\$ 26.4$ & & $\$ 31.3$ & & $\$ 33.6$ & & $\$ 15.8$ & & $\$ 30.5$ & & $\$ 26.7$ & \\
\hline SD & $\$ 21.8$ & & $\$ 35.5$ & & $\$ 35.6$ & & $\$ 23.0$ & & $\$ 26.8$ & & $\$ 27.4$ & \\
\hline \multicolumn{13}{|c|}{$\begin{array}{l}\text { aWeighted index in which a higher score indicates greater risk of mortality due to comorbid disease. }{ }^{20} \text { Measured during the } 1 \text {-year pre-index period using all available diag } \\
\text { nosis code fields on the claim. } \\
\text { bMeasured during the 1-year pre-index period. } \\
\text { cDefined as the number of unique medications with prescription days supplied inclusive of patient's index date (measured on index date). } \\
\text { dDefined as the patient copayment for the index prescription (measured on index date). } \\
\text { ARB = angiotensin II receptor blocker; HMO=health maintenance organization; OAB=overactive bladder; } P O S=\text { point of service; PPO=preferred provider organization; } \\
\text { SD =standard deviation. }\end{array}$} \\
\hline
\end{tabular}

point of service [POS], or unknown), payer type (commercial, Medicaid, Medicare "risk," self-insured, or unknown), history of pre-index period hospitalization (yes/no, as identified by revenue codes indicating room and board charges in the 1-year pre-index period), Charlson comorbidity score (a weighted index in which a higher score indicates greater risk of mortality due to comorbid disease, based on the 1-year pre-index period and all available diagnosis codes), index medication copay (the copayment for the first prescription of interest), and number of medications on hand at index date (defined as the total number of unique prescriptions with a days supplied value that included the index date). ${ }^{20}$

All data management and statistical analyses were completed using SAS (SAS Institute Inc., Cary, NC) versions 8.2 and 9.1. The a priori $P$ value for statistical significance was 0.05 .

\section{Results}

\section{Demographics}

After applying the study's inclusion and exclusion criteria, the following therapy cohorts were formed: 3,310 prostaglandin analog patients, 94,700 statin patients, 10,268 bisphosphonate patients, 22,031 oral antidiabetic patients, 29,876 ARB patients, and 7,722 OAB medication patients. Mean ages across all cohorts ranged from 43.7 years for patients on $\mathrm{OAB}$ medications to 56.9 years for patients on bisphosphonates (Table 2). The percentages of males in the bisphosphonate and $\mathrm{OAB}$ medication cohorts were low (5.5\% and $21.8 \%$, respectively), as these drugs are used predominately by women. In all other cohorts, the percentage of male patients ranged from $45 \%$ to $55 \%$. There were no dramatic differences in patient distribution for the cohorts 


\section{FIGURE 2 Time to Discontinuation ${ }^{a}$ of 6 Chronic Therapy Classes, Allowing for 60-Day Treatment Gap}

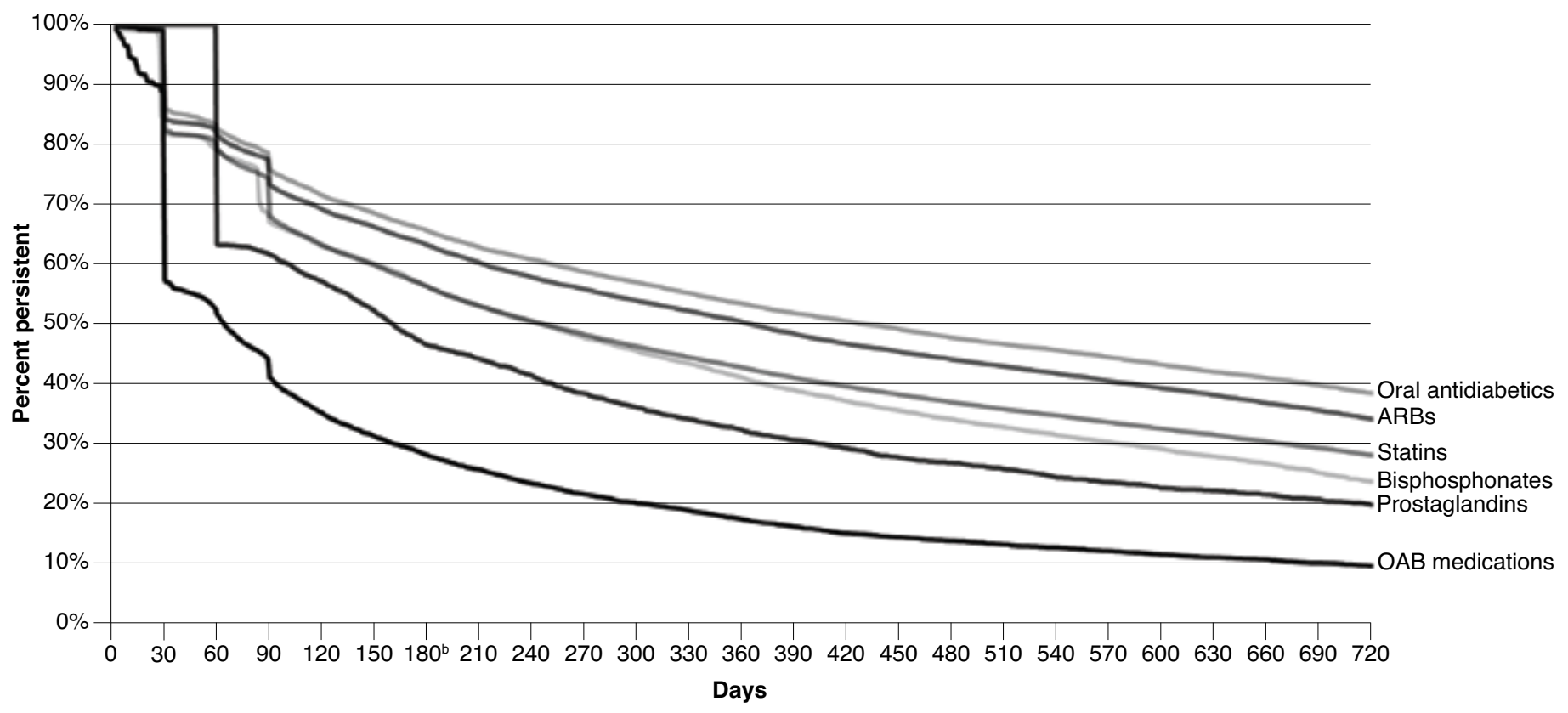

a Discontinuation was defined as the end of days supplied for an index medication class pharmacy claim immediately preceding a 60-day gap in therapy. A minimum of 12 months (maximum 24 months) continuous eligibility following the index date (day 0) was required. Beginning at day 390, the denominator for the calculation consisted of all remaining eligible patients with continuous enrollment through the end of the 30-day interval. Patients with continuous enrollment ending between day 360 and day 720 were censored at the point of their cessation of benefits.

${ }^{b} U$ sing the 60-day gap, 6-month persistence rates were prostaglandin analogs $47 \%$, statins $56 \%$, bisphosphonates 56\%, oral antidiabetics $66 \%$, ARBs $63 \%$, and OAB medications $28 \%$

$A R B=$ angiotensin II receptor blocker $O A B=$ overactive bladder.

with respect to geographic region, plan type, or payer type.

On average, patients taking oral antidiabetics scored slightly higher (mean $[\mathrm{SD}]=1.4[1.2]$ ) on the Charlson comorbidity index compared with patients in the other cohorts (means of 0.5-0.6). Prior to initiating their index therapy, patients in the oral antidiabetic medication cohort had a higher mean number of unique, pre-index medication prescriptions on their index date (3.4, compared with 2.6 to 3.1 for all other cohorts). More than $12 \%$ of patients in the $\mathrm{OAB}$ cohort $(12.4 \%)$ and $11.1 \%$ of patients in the oral antidiabetic cohort had at least 1 hospitalization in the year preceding treatment compared with less than $10 \%$ for all other cohorts (range of 6.3\%-9.9\%).

\section{Persistence}

At 6 months post-index, with the application of a 60-day refill grace period, persistence rates were $47 \%$ for prostaglandin analogs, $56 \%$ for statins, $56 \%$ for bisphosphonates, $66 \%$ for oral antidiabetics, $63 \%$ for ARBs, and 28\% for OAB medications (Figure 2). At 1 year, these rates decreased to 32\%, 43\%, 41\%, $54 \%, 50 \%$, and $18 \%$, respectively.
The trends and relative patterns of cohort persistence remained the same when adjusted for 30- and 90-day refill gaps (Figures 3 and 4). The lowest 6 -month persistence rates were consistently among patients taking prostaglandin analogs (35\% with 30-day gap; $57 \%$ with 90 -day gap) and $\mathrm{OAB}$ medications (21\% with 30-day gap; 32\% with 90-day gap), whereas patients taking oral antidiabetics had the highest persistence rates (53\% with 30-day gap; $72 \%$ with 90 -day gap). Rates of decline in persistence were relatively consistent from 6 months until the end of the maximum amount of patient follow-up time at 2 years.

Adjusted Odds of Nonpersistence. In the logistic regression model using the 60-day grace period, the adjusted odds of discontinuation during the 12-month post-index period were significantly lower for patients using oral antidiabetics than for the following groups: prostaglandin analog users (odds ratio $[\mathrm{OR}]=0.41,95 \%$ confidence interval $[\mathrm{CI}]=0.38-0.44, P<0.001$, statin users (OR=0.64, 95\% CI=0.62-0.66, $P<0.001)$, and bisphosphonate users $(\mathrm{OR}=0.63,95 \% \mathrm{CI}=0.60-0.66, P<0.001$; Table 3). Representing the greatest difference between groups, the odds of discontinuation were $79 \%$ lower for patients taking 


\section{FIGURE 3 Time to Discontinuation ${ }^{a}$ of 6 Chronic Therapy Classes, Allowing for 30-Day Treatment Gap}

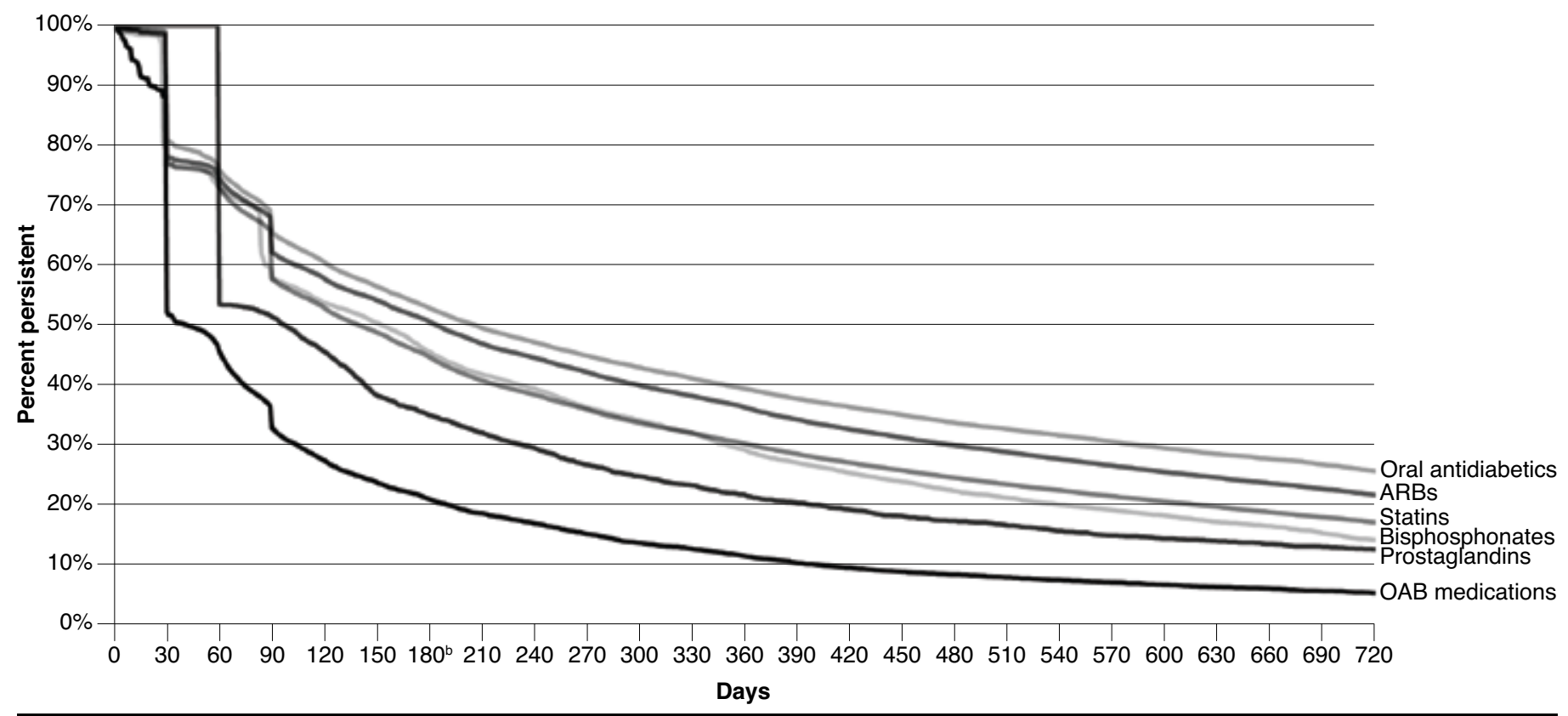

aDiscontinuation was defined as the end of days supplied for an index medication class pharmacy claim immediately preceding a 30-day gap in therapy. A minimum of 12 months (maximum 24 months) continuous eligibility following the index date (day 0) was required. Beginning at day 390, the denominator for the calculation consisted of all remaining eligible patients with continuous enrollment through the end of the 30-day interval. Patients with continuous enrollment ending between day 360 and day 720 were censored at the point of their cessation of benefits.

${ }^{b}$ Using the 30-day gap, 6-month persistence rates were prostaglandin analogs $35 \%$, statins $45 \%$, bisphosphonates $46 \%$, oral antidiabetics $53 \%$, ARBs $51 \%$, and OAB medications $21 \%$.

$A R B=$ angiotensin II receptor blocker; $O A B=$ overactive bladder.

oral antidiabetic medications than for $\mathrm{OAB}$ medication users $(\mathrm{OR}=0.21,95 \% \mathrm{CI}=0.20-0.23, \mathrm{P}<0.001)$. The logistic regression model's c-statistic (for predictive accuracy, where 0.50 means the model's accuracy is equivalent to random assignment and 1.0 means perfect prediction) was 0.642 . Cohort differences in the adjusted persistence measures remained significant when 30-day and 90-day grace periods were applied as refill gaps (data not shown).

Using age as a variable, with patients aged $35-44$ years as the reference group and applying the 30-, 60-, and 90-day gap allowances, the logistic regression model also showed that the risk of discontinuation declined in a mostly linear fashion with age. Applying a 60-day gap allowance, odds of discontinuation were $51 \%$ higher $(\mathrm{OR}=1.51,95 \% \mathrm{CI}=1.28-1.77)$ for patients aged 0-17 years compared with those aged 35-44 years (Table 3). Odds of discontinuation were lower for patients aged 65 years or older compared with those aged $35-44$ years $(\mathrm{OR}=0.51,95 \% \mathrm{CI}=0.40$ $0.66, P<0.001)$ and higher for patients in Medicare "risk" plans compared with those in commercial plans $(\mathrm{OR}=2.63,95 \%$ $\mathrm{CI}=2.07-3.34, P<0.001)$.

\section{Adherence}

Mean (SD) patient adherence by cohort, calculated as a continuous measure of PDC over a 12-month follow-up period, was as follows: 37\% (26\%) for prostaglandin analogs, 61\% (33\%) for statins, 60\% (34\%) for bisphosphonates, $72 \%$ (32\%) for oral antidiabetic drugs, $66 \%$ (32\%) for ARBs, and 35\% (32\%) for OAB medications (Table 4).

Adjusted Odds of Adherence. In logistic regression analysis adjusting for demographic and clinical characteristics, users of oral antidiabetic medications were significantly more likely to reach a PDC of at least $80 \%$ during 12 months of follow-up compared with users of other medications studied (Table 5). Adjusted odds ratios for oral antidiabetic drugs were 17.60 versus prostaglandin analogs (95\% CI=15.38-20.14, $P<0.001$ ), 2.06 versus statins $(95 \% \mathrm{CI}=1.99-2.12, P<0.001), 1.92$ versus bisphosphonates ( $95 \% \mathrm{CI}=1.83-2.02, P<0.001), 1.29$ versus ARBs (95\% $\mathrm{CI}=1.24-1.34, P<0.001)$, and 5.77 versus $\mathrm{OAB}$ medications (95\% $\mathrm{CI}=5.38-6.19, P<0.001$, Table 5). The logistic regression model's c-statistic (for predictive accuracy) was 0.676 . 


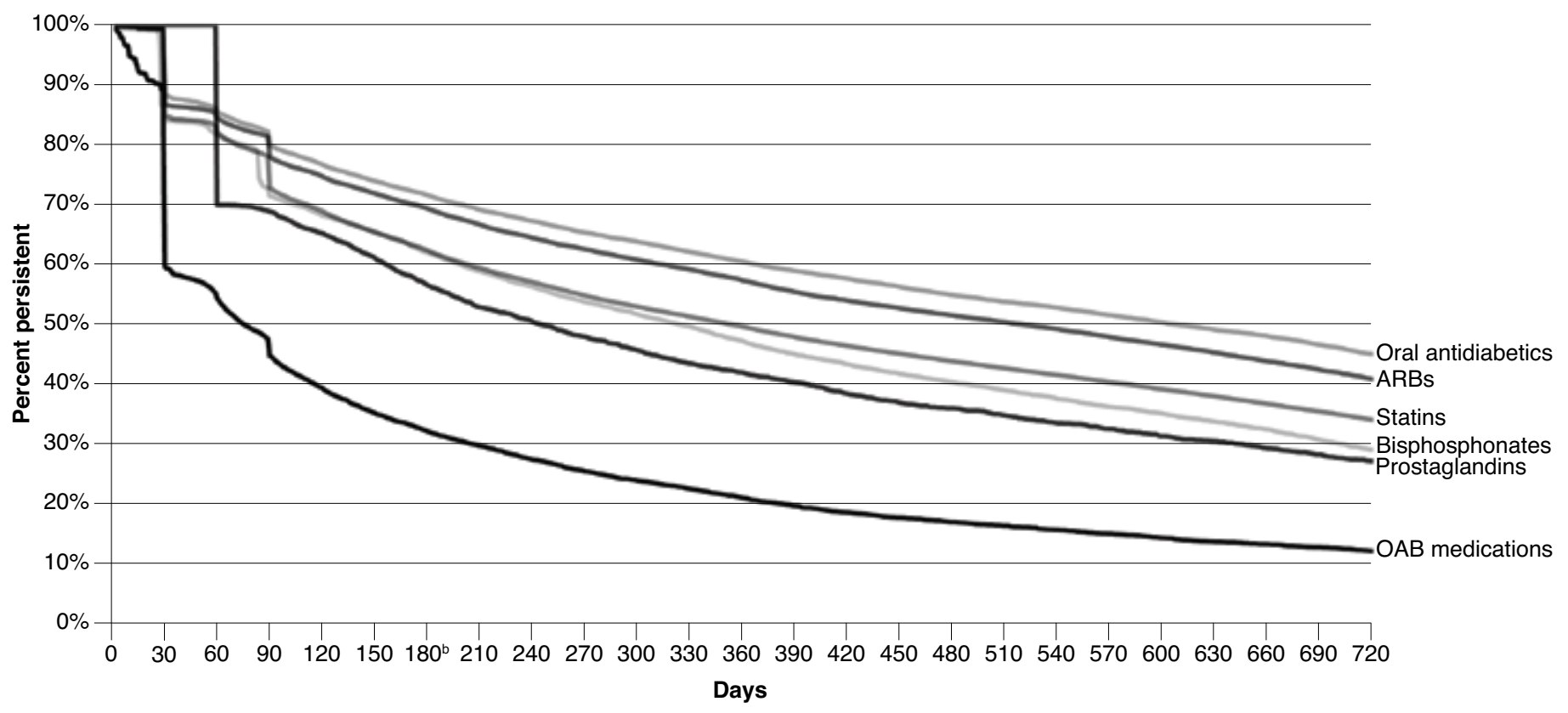

a Discontinuation was defined as the end of days supplied for an index medication pharmacy claim immediately preceding a 90-day gap in therapy. A minimum of 12 months (maximum 24 months) continuous eligibility following the index date (day 0) was required. Beginning at day 390, the denominator for the calculation consisted of all remaining eligible patients with continuous enrollment through the end of the 30-day interval. Patients with continuous enrollment ending between day 360 and day 720 were censored at the point of their cessation of benefits.

bUsing the 90-day gap, 6-month persistence rates were prostaglandin analogs $57 \%$, statins $62 \%$, bisphosphonates $62 \%$, oral antidiabetics $72 \%$, ARBs $69 \%$, and OAB medications $32 \%$.

$A R B=$ angiotensin II receptor blocker; $O A B=$ overactive bladder.

\section{Discussion}

$\overline{\text { We conducted a retrospective analysis of pharmacy claims to }}$ assess prescription drug adherence and persistence levels using consistent methods across 6 commonly used chronic therapeutic categories. The drug classes studied were representative of chronic medications for specific indications and widely used by a large portion of the population. Data were drawn from a database composed of multiple health plans that represent the adherence experience of Americans with commercial prescription insurance.

In all of the chronic therapy areas examined, persistence rates declined from initiation over the 2-year study period. Patients taking prostaglandin eye drops for glaucoma and those taking $\mathrm{OAB}$ medications showed the earliest and most rapid declines; throughout the study duration, persistence rates in these cohorts remained consistently and significantly lower than in all other cohorts analyzed.

Consistent with persistence findings, mean adherence (measured as PDC) was lowest in the OAB medications and prostaglandin analog cohorts (mean 35\% and 37\%, respectively) compared with all other drug cohorts, which had mean adherence rates of $60 \%-72 \%$. Logistic regression analyses of nonpersistence indicated that prostaglandins and OABs had significantly greater odds of discontinuation when compared with oral antidiabetic drugs. Odds ratios for discontinuation of therapy decreased in a mostly linear trend with age in groups aged 45-54 years or older and were significantly lower for patients aged 45 years or older compared with those 35-44 years of age. This trend in improved adherence with age is consistent with previous studies. $^{12,21-22}$ In addition, odds of discontinuation were higher in Medicare "risk" programs compared with commercial insurance programs. It should be noted, however, that the implementation of the Medicare Part D prescription program on January 1, 2006, occurred between the pre- and post-index periods of the current study; this change may have affected patient adherence and/or persistence during the overall study period for patients aged 65 years or older.

In the case of prostaglandin analogs, rates in adherence and persistence observed in this study may be related to the route of medication administration; eye drops may present greater selfadministration hurdles and may be easier to forget than pills, particularly if patients are already taking other oral medications. 
TABLE 3 Logistic Regression Analysis of Nonpersistence: Discontinuation of Index Therapy Class During 12-Month Post-Index Period

\begin{tabular}{|c|c|c|c|c|c|c|c|}
\hline \multirow[b]{2}{*}{ Variable } & \multirow[b]{2}{*}{ Coefficient } & \multirow{2}{*}{$\begin{array}{l}\text { Standard } \\
\text { Error }\end{array}$} & \multirow[b]{2}{*}{ Chi-Square } & \multirow[b]{2}{*}{$P$ Value } & \multirow[b]{2}{*}{ Odds Ratio } & \multicolumn{2}{|c|}{ 95\% Confidence Interval } \\
\hline & & & & & & Lower Limit & Upper Limit \\
\hline \multicolumn{8}{|l|}{ Drug group } \\
\hline Oral antidiabetic vs. prostaglandin analog & -0.8959 & 0.0406 & 486.3 & $<0.001$ & 0.41 & 0.38 & 0.44 \\
\hline Oral antidiabetic vs. statin & -0.4535 & 0.0161 & 793.1 & $<0.001$ & 0.64 & 0.62 & 0.66 \\
\hline Oral antidiabetic vs. bisphosphonate & -0.4659 & 0.0258 & 325.7 & $<0.001$ & 0.63 & 0.60 & 0.66 \\
\hline Oral antidiabetic vs. ARB & -0.0119 & 0.0189 & 0.4 & 0.527 & 0.99 & 0.95 & 1.03 \\
\hline Oral antidiabetic vs. OAB medication & -1.5414 & 0.0347 & 1969.0 & $<0.001$ & 0.21 & 0.20 & 0.23 \\
\hline \multicolumn{8}{|l|}{ Gender } \\
\hline Female vs. male & 0.1331 & 0.0106 & 157.3 & $<0.001$ & 1.14 & 1.12 & 1.17 \\
\hline \multicolumn{8}{|l|}{ Age group (years) } \\
\hline $0-17$ vs. $35-44$ & 0.4110 & 0.0826 & 24.8 & $<0.001$ & 1.51 & 1.28 & 1.77 \\
\hline $18-34$ vs. $35-44$ & 0.4002 & 0.0307 & 170.4 & $<0.001$ & 1.49 & 1.41 & 1.59 \\
\hline $45-54$ vs. $35-44$ & -0.3242 & 0.0159 & 416.3 & $<0.001$ & 0.72 & 0.70 & 0.75 \\
\hline $55-64$ vs. $35-44$ & -0.5794 & 0.0158 & 1347.3 & $<0.001$ & 0.56 & 0.54 & 0.58 \\
\hline 65 or older vs. $35-44$ & -0.6663 & 0.1259 & 28.0 & $<0.001$ & 0.51 & 0.40 & 0.66 \\
\hline \multicolumn{8}{|l|}{ Region } \\
\hline East vs. West & 0.1637 & 0.0298 & 30.2 & $<0.001$ & 1.18 & 1.11 & 1.25 \\
\hline Midwest vs. West & -0.2012 & 0.0279 & 51.8 & $<0.001$ & 0.82 & 0.77 & 0.86 \\
\hline South vs. West & 0.2747 & 0.0283 & 94.5 & $<0.001$ & 1.32 & 1.25 & 1.39 \\
\hline \multicolumn{8}{|l|}{ Plan type } \\
\hline Indemnity vs. HMO & -0.0887 & 0.0254 & 12.2 & $<0.001$ & 0.92 & 0.87 & 0.96 \\
\hline PPO vs. HMO & -0.0901 & 0.0128 & 49.7 & $<0.001$ & 0.91 & 0.89 & 0.94 \\
\hline POS vs. HMO & -0.0453 & 0.0188 & 5.8 & 0.016 & 0.96 & 0.92 & 0.99 \\
\hline Unknown vs. HMO & -0.4456 & 0.0305 & 213.7 & $<0.001$ & 0.64 & 0.60 & 0.68 \\
\hline \multicolumn{8}{|l|}{ Payer type } \\
\hline Medicaid vs. commercial & 0.6226 & 0.0804 & 59.9 & $<0.001$ & 1.86 & 1.59 & 2.18 \\
\hline Medicare risk vs. commercial & 0.9668 & 0.1213 & 63.5 & $<0.0001$ & 2.63 & 2.07 & 3.34 \\
\hline Self-insured vs. commercial & -0.0983 & 0.0317 & 9.6 & 0.002 & 0.91 & 0.85 & 0.96 \\
\hline Unknown vs. commercial & 0.5759 & 0.0839 & 47.1 & $<0.001$ & 1.78 & 1.51 & 2.10 \\
\hline History of hospitalization (yes vs. no)a & 0.1367 & 0.0184 & 55.4 & $<0.001$ & 1.15 & 1.11 & 1.19 \\
\hline Comorbidity score $^{\mathrm{b}}$ & 0.0388 & 0.0050 & 59.4 & $<0.001$ & 1.04 & 1.03 & 1.05 \\
\hline Copay of index medication ${ }^{c}$ & 0.0040 & 0.0002 & 513.6 & $<0.001$ & 1.00 & 1.00 & 1.00 \\
\hline Number of medications at index ${ }^{\mathrm{d}}$ & -0.0471 & 0.0027 & 311.2 & $<0.001$ & 0.95 & 0.95 & 0.96 \\
\hline \multicolumn{8}{|c|}{$\begin{array}{l}\text { Note: } N \text { of cases included in the model }=167,885 . \text { Model c-statistic }=0.642 . \\
\text { a Measured during the 1-vear pre-index period. }\end{array}$} \\
\hline \multicolumn{8}{|c|}{$\begin{array}{l}{ }^{b} \text { Charlson Comorbidity Score, a weighted index in which a higher score indicates greater risk of mortality due to comorbid disease. }{ }^{20} \text { Measured during the } 1 \text {-year } \\
\text { pre-index period using all available diagnosis code fields on the claim. }\end{array}$} \\
\hline \multicolumn{8}{|c|}{ 'Defined as the patient copayment for the index prescription (measured on index date). } \\
\hline \multicolumn{8}{|c|}{ 'Defined as the number of unique medications with prescription days supplied inclusive of patient's index date (measured on index date). } \\
\hline $\begin{array}{l}\text { ARB = angiotensin II receptor blocker; } H M O=\text { hea } \\
\text { organization. }\end{array}$ & intenance organ & ation; $O A B=$ & veractive bladde & $O S=$ point $\mathrm{c}$ & iervice; $P P O=p$ & erred provider & \\
\hline
\end{tabular}

\section{TABLE 4 Adherence (Continuous Measure) with 6 Chronic} Therapy Classes During 12-Month Post-Index Period

\begin{tabular}{|c|c|c|c|c|c|c|}
\hline & $\begin{array}{c}\text { Prostaglandin } \\
\text { Analogs }\end{array}$ & Statins & Bisphosphonates & $\begin{array}{c}\text { Oral } \\
\text { Antidiabetics }\end{array}$ & ARBs & $\begin{array}{c}\mathrm{OAB} \\
\text { Medications }\end{array}$ \\
\hline & $(\mathrm{n}=3,310)$ & $(\mathrm{n}=94,700)$ & $(n=10,268)$ & $(\mathrm{n}=22,031)$ & $(n=29,876)$ & $(\mathbf{n}=7,722)$ \\
\hline \multicolumn{7}{|c|}{ Proportion of days covered } \\
\hline Mean & 0.37 & 0.61 & 0.60 & 0.72 & 0.66 & 0.35 \\
\hline SD & 0.26 & 0.33 & 0.34 & 0.32 & 0.32 & 0.32 \\
\hline Median & 0.33 & 0.67 & 0.68 & 0.87 & 0.75 & 0.24 \\
\hline
\end{tabular}




\section{TABLE 5 Logistic Regression Analysis of Adherence: At Least 80\% PDC for} Index Medication Class During 12-Month Post-Index Period

\begin{tabular}{|c|c|c|c|c|c|c|c|}
\hline \multirow[b]{2}{*}{ Variable } & \multirow[b]{2}{*}{ Coefficient } & \multirow{2}{*}{$\begin{array}{l}\text { Standard } \\
\text { Error }\end{array}$} & \multirow[b]{2}{*}{ Chi-Square } & \multirow[b]{2}{*}{$P$ Value } & \multirow[b]{2}{*}{ Odds Ratio } & \multicolumn{2}{|c|}{ 95\% Confidence Interval } \\
\hline & & & & & & Lower Limit & Upper Limit \\
\hline \multicolumn{8}{|l|}{ Drug group } \\
\hline Oral antidiabetic vs. prostaglandin analog & 2.8682 & 0.0688 & 1739.5 & $<0.001$ & 17.60 & 15.38 & 20.14 \\
\hline Oral antidiabetic vs. statin & 0.7206 & 0.0164 & 1926.3 & $<0.001$ & 2.06 & 1.99 & 2.12 \\
\hline Oral antidiabetic vs. bisphosphonate & 0.6532 & 0.0262 & 619.8 & $<0.001$ & 1.92 & 1.83 & 2.02 \\
\hline Oral antidiabetic vs. ARB & 0.2534 & 0.0191 & 175.4 & $<0.001$ & 1.29 & 1.24 & 1.34 \\
\hline Oral antidiabetic vs. OAB medication & 1.7522 & 0.0359 & 2382.8 & $<0.001$ & 5.77 & 5.38 & 6.19 \\
\hline \multicolumn{8}{|l|}{ Gender } \\
\hline Female vs. male & -0.1399 & 0.0109 & 164.7 & $<0.001$ & 0.87 & 0.85 & 0.89 \\
\hline Age group (years) & -0.3066 & 0.0875 & 12.3 & $<0.001$ & 0.74 & 0.62 & 0.87 \\
\hline $0-17$ vs. $35-44$ & -0.3369 & 0.0322 & 109.2 & $<0.001$ & 0.71 & 0.67 & 0.76 \\
\hline $18-34$ vs. $35-44$ & 0.3850 & 0.0166 & 540.0 & $<0.001$ & 1.47 & 1.42 & 1.52 \\
\hline $45-54$ vs. $35-44$ & 0.7487 & 0.0164 & 2081.7 & $<0.001$ & 2.11 & 2.05 & 2.18 \\
\hline $55-64$ vs. $35-44$ & 0.7344 & 0.1279 & 33.0 & $<0.001$ & 2.08 & 1.62 & 2.68 \\
\hline \multicolumn{8}{|l|}{65 or older vs. $35-44$} \\
\hline \multicolumn{8}{|l|}{ Region } \\
\hline East vs. West & -0.0235 & 0.0305 & 0.6 & 0.440 & 0.98 & 0.92 & 1.04 \\
\hline Midwest vs. West & 0.3432 & 0.0286 & 144.1 & $<0.001$ & 1.41 & 1.33 & 1.49 \\
\hline South vs. West & -0.3664 & 0.0290 & 159.6 & $<0.001$ & 0.69 & 0.66 & 0.73 \\
\hline \multicolumn{8}{|l|}{ Plan type } \\
\hline Indemnity vs. HMO & 0.1705 & 0.0258 & 43.6 & $<0.001$ & 1.19 & 1.13 & 1.25 \\
\hline $\mathrm{PPO}$ vs. HMO & 0.2401 & 0.0132 & 330.5 & $<0.001$ & 1.27 & 1.24 & 1.31 \\
\hline POS vs. HMO & 0.1114 & 0.0192 & 33.5 & $<0.001$ & 1.12 & 1.08 & 1.16 \\
\hline Unknown vs. HMO & 0.5554 & 0.0313 & 315.6 & $<0.001$ & 1.74 & 1.64 & 1.85 \\
\hline \multicolumn{8}{|l|}{ Payer type } \\
\hline Medicaid vs. commercial & -0.6035 & 0.0846 & 50.9 & $<0.001$ & 0.55 & 0.46 & 0.65 \\
\hline Medicare risk vs. commercial & -0.8372 & 0.1229 & 46.4 & $<0.001$ & 0.43 & 0.34 & 0.55 \\
\hline Self-insured vs. commercial & 0.1086 & 0.0324 & 11.2 & $<0.001$ & 1.12 & 1.05 & 1.19 \\
\hline Unknown vs. commercial & -0.4871 & 0.0851 & 32.8 & $<0.001$ & 0.61 & 0.52 & 0.73 \\
\hline History of hospitalization (yes vs. no)a & -0.1073 & 0.0188 & 32.7 & $<0.001$ & 0.90 & 0.87 & 0.93 \\
\hline Comorbidity score $^{\mathrm{b}}$ & -0.0275 & 0.0051 & 28.7 & $<0.001$ & 0.97 & 0.96 & 0.98 \\
\hline Copay of index medication ${ }^{c}$ & -0.0030 & 0.0002 & 295.0 & $<0.001$ & 1.00 & 1.00 & 1.00 \\
\hline Number of medications at index ${ }^{\mathrm{d}}$ & 0.0759 & 0.0027 & 766.8 & $<0.001$ & 1.08 & 1.07 & 1.09 \\
\hline \multicolumn{8}{|c|}{ Note: $N$ of cases included in the model $=167,885$. Model c-statistic $=0.676$. } \\
\hline \multicolumn{8}{|c|}{ a Measured during the 1-year pre-index period. } \\
\hline \multicolumn{8}{|c|}{$\begin{array}{l}\text { bCharlson Comorbidity Score, a weighted index in which a higher score indicates greater risk of mortality due to comorbid disease. }{ }^{20} \text { Measured during the 1-year pre-index } \\
\text { period using all available diagnosis code fields on the claim. }\end{array}$} \\
\hline \multicolumn{8}{|c|}{ 'Defined as the patient copayment for the index prescription (measured on index date). } \\
\hline \multicolumn{8}{|c|}{ dDefined as the number of unique medications with prescription days supplied inclusive of patient's index date (measured on index date). } \\
\hline \multicolumn{8}{|c|}{$\begin{array}{l}A R B=\text { angiotensin II receptor blocker; } H M O=\text { health maintenance organization; } O A B=\text { overactive bladder; } P D C=\text { proportion of days covered; } P O S=\text { point of service; } \\
P P O=\text { preferred provider organization. }\end{array}$} \\
\hline
\end{tabular}

Such difficulties may influence administration and/or persistence and indicate that patients new to these therapies may require extra education to increase their likelihood of treatment success. ${ }^{23-24}$ In the case of OAB medications, which are relatively new treatment options, a prior study by Campbell et al. (2007) found that patients cited a lack of efficacy, prescription costs, and side effects as the primary reasons for discontinuation. ${ }^{25}$

The present study's results are generally in line with those of prior studies showing suboptimal drug use patterns in the evaluated drug classes. However, the majority of previous studies have been limited to a single drug class or therapeutic area. ${ }^{5,7-11,17,21-22,26}$ In one exception, Briesacher et al. (2008) used pharmacy claims database records to study MPRs—but not persistence-among 7 disease cohorts (gout, hypercholesterolemia, hypertension, hypothyroidism, osteoporosis, seizure disorders, and type 2 diabetes mellitus)..$^{12}$ In disease cohorts similar to those in the present study, Briesacher et al. found adherence rates (defined as MPR of at least $80 \%$ ) of $55 \%$ for hypercholesterolemia, $72 \%$ for hypertension, $51 \%$ for osteoporosis, and $66 \%$ for type 2 diabetes mellitus. ${ }^{12}$ To our knowledge, the present study is the first to measure PDC 
across multiple chronic conditions and therapies.

We observed variations in persistence and adherence among the sample therapeutic classes, which may be illustrative of the variation across all chronic therapies and which may provide useful baseline information to guide the development of quality improvement initiatives. There is ample evidence to suggest that inadequate treatment of chronic illness can have significant consequences to patient health, including serious adverse outcomes and comorbid conditions. For example, poorly treated diabetes can lead to micro- and macrovascular disease; poorly controlled hypertension may lead to cardiovascular disease and kidney failure; untreated glaucoma may lead to deterioration of vision and reduced quality of life; and so on. In turn, increased medical requirements necessitated by either suboptimal treatment or potentially avoidable chronic disease sequelae lead to increased costs, increased health care utilization, and increased susceptibility to adverse drug reactions. ${ }^{27-36}$ In a longitudinal cohort study conducted by Balkrishnan et al. (2006), OAB patients experienced a $5.6 \%$ reduction in annual health care costs for every $10 \%$ increase in MPR. ${ }^{36}$

By comparing across 6 chronic therapeutic areas, the present study confirms that room for improvement in drug persistence and adherence exists across a range of conditions. This finding is in concordance with previous analyses indicating that chronic conditions present particular difficulties for medication adherence and persistence. ${ }^{37-38}$ Quality improvement initiatives should begin by prioritizing therapy areas where the impact of nonadherence is the most costly in clinical and economic terms. Though we found that adherence with glaucoma and OAB therapies was lower than with the other categories studied, further study is needed to understand the relative clinical and economic effects of nonadherence and thus the potential benefits of improving adherence. Next, scaleable, evidence-based programs that address the underlying reasons for nonadherence in priority therapy areas must be developed, implemented, and evaluated. In the case of glaucoma, for example, existing studies suggest that nonadherence is associated with poor patient-physician communication, poor patient education, patient perceptions that the therapy is ineffective, and difficulty administering eye drops. ${ }^{37-42}$

Efforts to improve the quality of drug therapy management require more and better information on the underlying phenomena of adherence and persistence to prescribed therapy. Driven in part by such needs, additional adherence and persistence measures are currently being developed by organizations such as the Pharmacy Quality Alliance and the National Quality Forum, both of which recognize that improved drug use patterns are a step toward health care optimization. ${ }^{43-45}$

\section{Limitations}

First, PDC calculations may overestimate adherence, as they are based on the assumption that patients take all medications for which they have prescriptions filled. Second, adherence and/or persistence calculations do not account for the possibility that patients acquired prescription medications from sources other than the pharmacies included in the database, such as physician samples. Third, since this study includes medications administered through different means (e.g., pills and eye drops), some imperfections likely exist in the calculation of use of prostaglandin analog eye drops. In particular, PDC and discontinuation dates of eye drops may be susceptible to variability due to liquid loss during use (spillage, imperfect administration). However, we endeavored to minimize these variables by limiting included prescriptions to $2.5 \mathrm{ml}$ bottles of prostaglandin analogs with an assumed 60-day supply. In addition, to account for potential variation to the greatest degree possible, we calculated persistence using multiple refill grace periods (30,60, and 90 days). The fact that relative persistence rates in the 6 cohorts remained consistent across grace periods indicates that our methodology may have overcome this limitation.

\section{Conclusion}

This analysis of adherence (PDC) and persistence across a sample of 6 chronic therapies found variable but uniformly suboptimal medication use patterns. Adherence to prostaglandin eye drops and $\mathrm{OAB}$ medications was lower than to cardiovascular, oral antidiabetic, and oral osteoporosis therapies. These findings provide useful baseline information for the development of initiatives to improve the quality of drug therapy management.

\section{Authors}

JASON YEAW, MPH, is Director, Health Economics and Outcomes Research, IMS Health, Watertown, Massachusetts. JOSHUA S. BENNER, PharmD, ScD, is Research Director, Engelberg Center for Health Care Reform, The Brookings Institution, Washington, DC. JOHN G. WALT, MBA, is Manager, Global Health Outcomes Strategy and Research, Allergan, Inc., Irvine, California. SERGEY SIAN, PhD, is Statistical Programmer; and DANIEL B. SMITH, MA, is Senior Statistical Programmer, IMS Health, Watertown, Massachusetts.

AUTHOR CORRESPONDENCE: Jason Yeaw, MPH, IMS Health, 311 Arsenal St., Watertown, MA 02472. Tel.: 617.393.8352;

Fax: 617.972.8587; E-mail: jyeaw@us.imshealth.com.

\section{DISCLOSURES}

This study was sponsored by Allergan, Inc. Walt is an employee of Allergan, and the 3 IMS-employed authors reported receipt of consulting fees from Allergan. Allergan was involved in the concept, interpretation, revision, and approval of the manuscript but had no role in the collection or analysis of the data.

The authors thank medical writer Caitlin Rothermel, MA, MPHc, for her assistance in the preparation of this manuscript and Arliene Ravelo, MPH, for her assistance in the concept and data interpretation of the study. 
Concept and design were the work of Yeaw, Benner, and Walt, with the assistance of Ravelo. Data collection was performed by Smith and Sian, and data interpretation by Yeaw and Benner with the assistance of Ravelo. The manuscript was written primarily by Yeaw, with the assistance of Benner, Rothermel, and Walt. The manuscript was revised by Yeaw, with the assistance of Benner and Rothermel.

\section{REFERENCES}

1. World Health Organization. Adherence to long-term therapies: evidence for action. January 2003. Available at: http://www.who.int/chp/knowledge/ publications/adherence_report/en/index.html. Accessed November 13, 2009.

2. New England Healthcare Institute. Thinking outside the pillbox: a system-wide approach to improving patient medication adherence for chronic disease. August 12, 2009. Available at: http://www.nehi.net/publications/44/ thinking_outside_the_pillbox_a_systemwide_approach_to_improving patient_medication_adherence_for_chronic_disease. Accessed November 13, 2009.

3. National Council on Patient Information and Education. Enhancing prescription medicine adherence: a national action plan. August 2007. Available at: http://www.talkaboutrx.org/documents/enhancing_prescription_medicine_adherence.pdf. Accessed November 13, 2009.

4. National Quality Forum. National Quality Forum endorses measures to improve medication safety and quality. August 17, 2009. Available at: http://www.qualityforum.org/News_And_Resources/Press_Releases/2009/ National_Quality_Forum_Endorses_Measures_to_Improve_Medication_ Safety_and_Quality.aspx. Accessed November 13, 2009.

5. Benner JS, Glynn RJ, Mogun H, Neumann PJ, Weinstein MC, Avorn J. Long-term persistence in use of statin therapy in elderly patients. JAMA. 2002;288(4):455-61. Available at: http://jama.ama-assn.org/cgi/content/ full/288/4/455. Accessed November 13, 2009.

6. Jackevicius CA, Mamdani M, Tu JV. Adherence with statin therapy in elderly patients with and without acute coronary syndromes. JAMA. 2002;288(4):462-67. Available at: http://jama.ama-assn.org/cgi/content/ full/288/4/462. Accessed November 13, 2009.

7. Reardon G, Schwartz GF, Mozaffari E. Patient persistency with ocular prostaglandin therapy: a population-based, retrospective study. Clin Ther. 2003;25(4):1172-85.

8. Cramer JA, Mattson RH, Prevey ML, Scheyer RD, Ouellette VL. How often is medication taken as prescribed? A novel assessment technique. JAMA. 1989;261(22):3273-77.

9. Avorn J, Monette J, Lacour A, et al. Persistence of use of lipid-lowering medications: a cross-national study. JAMA. 1998;279(18):1458-62. Available at: http://jama.ama-assn.org/cgi/content/full/279/18/1458. Accessed November 13, 2009.

10. Weycker D, Macarios D, Edelsberg J, Oster G. Compliance with drug therapy for postmenopausal osteoporosis. Osteoporos Int. 2006;17(11):164552.

11. Wogen J, Kreilick CA, Livornese RC, Yokoyama K, Frech F. Patient adherence with amlodipine, lisinopril, or valsartan therapy in a usual-care setting. J Manag Care Pharm. 2003;9(5):424-29. Available at: http://www. amcp.org/data/jmcp/Research-424-429.pdf.

12. Briesacher BA, Andrade SE, Fouayzi H, Chan KA. Comparison of drug adherence rates among patients with seven different medical conditions. Pharmacotherapy. 2008;28(4):437-43.

13. Vinker S, Shani M, Baevsky T, Elhayany A. Adherence with statins over 8 years in a usual care setting. Am J Manag Care. 2008;14(6):388-92. Available at: http://www.ajmc.com/issue/managed-care/2008/2008-06voll4-n6/Jun08-3302p388-392. Accessed November 13, 2009.
14. Cotté FE, Fardellone P, Mercier F, Gaudin AF, Roux C. Adherence to monthly and weekly oral bisphosphonates in women with osteoporosis. Osteoporos Int. 2009 May 21. (Epub ahead of print).

15. Cramer JA. A systematic review of adherence with medications for diabetes. Diabetes Care. 2004;27(5):1218-24. Available at: http://care.diabetesjournals.org/content/27/5/1218.long. Accessed November 13, 2009.

16. Vrijens B, Vincze G, Kristanto P, Urquhart J, Burnier M. Adherence to prescribed antihypertensive drug treatments: longitudinal study of electronically compiled dosing histories. BMJ. 2008;336(7653):1114-17. Available at: http://www.ncbi.nlm.nih.gov/pmc/articles/PMC2386633/?tool=pubmed. Accessed November 13, 2009.

17. Yu YF, Nichol MB, Yu AP, Ahn J. Persistence and adherence of medications for chronic overactive bladder/urinary incontinence in the California Medicaid program. Value Health. 2005;8(4):495-505.

18. Okeke CO, Quigley HA, Jampel HD, et al. Interventions improve poor adherence with once daily glaucoma medications in electronically monitored patients. Ophthalmology. 2009 Oct 6. (Epub ahead of print).

19. IMS Lifelink: Patient-centered disease and treatment insights. Available for purchase at: http://www.imshealth.com/portal/site/imshealth/menuitem. a953aef4d73dlecd88f611019418c22a/?vgnextoid $=5$ f70beb3a50d6110VgnVC M10000071812ca2RCRD. Accessed November 13, 2009.

20. Charlson ME, Pompei P, Ales KL, MacKenzie CR. A new method of classifying prognostic comorbidity in longitudinal studies: development and validation. J Chronic Dis. 1987;40(5):373-83.

21. Grant RW, O'Leary KM, Weilburg JB, Singer DE, Meigs JB. Impact of concurrent medication use on statin adherence and refill persistence. Arch Intern Med. 2004;164(21):2343-48

22. Walker EA, Molitch M, Kramer MK, et al. Adherence to preventive medications: predictors and outcomes in the Diabetes Prevention Program. Diabetes Care. 2006;29(9):1997-2002.

23. Tsai T, Robin AL, Smith JP, 3rd. An evaluation of how glaucoma patients use topical medications: a pilot study. Trans Am Ophthalmol Soc. 2007;105:2933

24. Sleath B, Robin AL, Covert D, Byrd JE, Tudor G, Svarstad B. Patientreported behavior and problems in using glaucoma medications. Ophthalmology. 2006;113(3):431-36.

25. Campbell UB, Stang P, Barron R. Survey assessment of continuation of and satisfaction with pharmacological treatment for urinary incontinence. Value Health. 2008:11(4):726-32.

26. Shaya FT, Blume S, Gu A, Zyczynski T, Jumadilova Z. Persistence with overactive bladder pharmacotherapy in a Medicaid population. Am J Manag Care. 2005;11(4 Suppl):S121-29.

27. Brown JS, Vittinghoff E, Wyman JF, et al. Urinary incontinence: does it increase risk for falls and fractures? Study of Osteoporotic Fractures Research Group. J Am Geriatr Soc. 2000;48(7):721-25.

28. Centers for Disease Control and Prevention. National diabetes fact sheet: general information and national estimates on diabetes in the United States, 2003. Rev ed. Atlanta, GA: U.S. Department of Health and Human Services, Centers for Disease Control and Prevention; 2004. Available at: http://www. cdc.gov/diabetes/pubs/pdf/ndfs_2003.pdf. Accessed November 13, 2009.

29. Col N, Fanale JE, Kronholm P. The role of medication noncompliance and adverse drug reactions in hospitalizations of the elderly. Arch Intern Med. 1990;150(4):841-45.

30. Cranney A, Jamal SA, Tsang JF, Josse RG, Leslie WD. Low bone mineral density and fracture burden in postmenopausal women. CMAJ. 2007;177(6):575-80.

31. Darkow T, Fontes CL, Williamson TE. Costs associated with the management of overactive bladder and related comorbidities. Pharmacotherapy. 2005;25(4):511-19. 
32. Grundy SM, Balady GJ, Criqui MH, et al. Primary prevention of coronary heart disease: guidance from Framingham: a statement for healthcare professionals from the AHA Task Force on Risk Reduction. American Heart Association. Circulation. 1998;97(18):1876-87.

33. Hu TW, Wagner TH, Bentkover JD, Leblanc K, Zhou SZ, Hunt T. Costs of urinary incontinence and overactive bladder in the United States: a comparative study. Urology. 2004;63(3):461-65.

34. U.S. Department of Health and Human Services, National Institutes of Health, National Heart Lung and Blood Institute, National High Blood Pressure Education Program. The seventh report of the Joint National Committee on Prevention, Detection, Evaluation, and Treatment of High Blood Pressure. Bethesda, MD: National Institutes of Health; 2004:NIH Publication No. 04-5230. Available at: http://www.nhlbi.nih.gov/guidelines/ hypertension/jnc7full.pdf. Accessed November 13, 2009.

35. Yusuf S, Hawken S, Ounpuu S, et al. Effect of potentially modifiable risk factors associated with myocardial infarction in 52 countries (the INTERHEART study): case-control study. Lancet. 2004;364(9438):937-52.

36. Balkrishnan R, Bhosle MJ, Camacho FT, Anderson RT. Predictors of medication adherence and associated health care costs in an older population with overactive bladder syndrome: a longitudinal cohort study. J Urol. 2006;175(3 Pt 1):1067-71.

37. Haynes R, Ackloo E, Sahota N, McDonald H, Yao X. Interventions for enhancing medication adherence. Cochrane Database Syst Rev. 2008(2):CD000011.
38. Haynes RB, McKibbon KA, Kanani R. Systematic review of randomised trials of interventions to assist patients to follow prescriptions for medications. Lancet. 1996;348(9024):383-86.

39. McDonald HP, Garg AX, Haynes RB. Interventions to enhance patient adherence to medication prescriptions: scientific review. JAMA. 2002;288(22):2868-79. Available at: http://jama.ama-assn.org/cgi/content/ full/288/22/2868. Accessed November 13, 2009 .

40. Friedman DS, Hahn SR, Gelb L, et al. Doctor-patient communication, health-related beliefs, and adherence in glaucoma results from the Glaucoma Adherence and Persistency Study. Ophthalmology. 2008;115(8):1320-27,1327.

41. Lacey J, Cate H, Broadway DC. Barriers to adherence with glaucoma medications: a qualitative research study. Eye (Lond). 2009;23(4):924-32.

42. Tsai JC. Medication adherence in glaucoma: approaches for optimizing patient compliance. Curr Opin Ophthalmol. 2006;17(2):190-95.

43. National Quality Forum. National voluntary consensus standards for the reporting of therapeutic drug management quality. Available at: http://216.122.138.39/projects/ongoing/therapeutic.asp. Accessed April 10, 2008.

44. National Quality Forum. Improving use of prescription medications: a national action plan. Executive summary. Washington, DC: National Quality Forum; 2005.

45. Pharmacy Quality Alliance. November 20, 2006 meeting: endorsed measures, survey instruments and reports. Available at: http://www.pqaalliance. org/nov20meeting.htm. Accessed November 13, 2008. 